\title{
Tapping and Peg Insertion after Levodopa Intake in Treated and de novo Parkinsonian Patients
}

\author{
Thomas Müller, Sabiene Benz, Horst Przuntek
}

\begin{abstract}
Background: Investigators use instrumental tasks for objective assessment of parkinsonian motor disability and its drug response. To date, such studies on treated parkinsonian patients have not addressed acute and long-term effects of dopaminergic drugs. Objectives: To determine the impact of long-term dopaminergic therapy within a standardized levodopa challenge test design in combination with two repeatedly performed instrumental tasks, peg insertion and tapping, in previously treated and untreated parkinsonian patients. Results: Tapping significantly deteriorated in previously untreated, but not in treated parkinsonian patients after levodopa intake. In contrast, motor symptoms and peg insertion significantly improved in both groups of parkinsonian patients. Results of both tests differed between parkinsonian patients and matched controls. Conclusion: Worsening of cognitively less demanding tapping may result from upregulated presynaptic inhibitory feedback regulation, sedative effects of levodopa or dopamine overflow in untreated parkinsonian patients, who are sensitive to these effects in contrast to treated parkinsonian patients. Tapping is a task with autonomic repetitive performance and programming of standardised movements with a low need for cognitive effort. This autonomic functioning of attentional control and selective processing is intact in Parkinson's disease. Peg insertion depends on more complex movements and thus hypothetically on dopamine-associated cognitive processes. Therefore, impairment of peg insertion responded to dopaminergic stimulation in both groups of parkinsonian patients. Future studies on the efficacy of antiparkinsonian drugs, using instrumental tasks for objective assessment, should consider long-term impact of antiparkinsonian drug therapy and associated cognitive efforts.
\end{abstract}

RÉSUMÉ: Le tapping et l'insertion de chevilles sur une planchette après l'administration de lévodopa chez des patients parkinsoniens traités et naïfs. Introduction: Les investigateurs utilisent des appareils comme outils d'évaluation objective de l'invalidité motrice et de la réponse thérapeutique chez les parkinsoniens. Jusqu'à maintenant, de telles études chez des parkinsoniens traités n'ont pas évalué les effets aigus et à long terme des médicaments dopaminergiques. Objectives: L'étude vise à déterminer l'impact de la thérapie dopaminergique à long terme dans le cadre d'un test standardisé de provocation à la lévodopa effectué en combinaison avec deux tâches, l'insertion de chevilles sur une planchette et le tapping, chez des parkinsoniens traités et non traités antérieurement. Résultats: Le tapping se détériore significativement après l'administration de lévodopa chez les parkinsoniens non traités contrairement aux parkinsoniens traités. Par contre, les symptômes moteurs et l'insertion de chevilles sur une planchette s'amélioraient significativement dans les deux groupes de parkinsoniens. Les résultats des deux tests étaient différents chez les parkinsoniens et les contrôles appariés. Conclusion: Une détérioration du tapping, qui est moins exigeant au point de vue cognitif, peut résulter d'une régulation à la hausse de la rétroinhibition présynaptique, des effets sédatifs de la lévodopa ou à un excédent de dopamine chez les parkinsoniens non traités. Par contre, l'altération de l'insertion de l'insertion de chevilles sur une planchette, une tache plus exigeante au point de vue cognitif, a répondu à la stimulation dopaminergique chez les parkinsoniens. D'autres études sur l'efficacité des antiparkinsoniens au moyen d'outils pour l'évaluation objective devraient considérer l'impact à long terme des agents antiparkinsoniens et des efforts cognitifs associés.

Can. J. Neurol. Sci. 2002; 29: 73-77

Neurological examination of parkinsonian symptomatology uses various procedures for evaluation of the function of the extrapyramidal motor system. ${ }^{1,2}$ Typically, clinical rating scales are employed, but they suffer from interrater variability, relative insensitivity to subtle modifications of the disease and/or the subjective impact of the scoring examiner. ${ }^{1,3-5}$ Therefore, investigators developed complex quantitative instruments that objectively assess tremor and motor slowness but may only partially reflect all of the major motor symptoms of Parkinson's disease (PD) ${ }^{6,7}$ In contrast, peg insertion with the Purdue pegboard shows a good test-retest reliability and correlates with the dopaminergic nigrostriatal deficit in PD. ${ }^{8-10}$ Tapping also assesses motor impairment and response to antiparkinsonian drugs. ${ }^{11-14}$ Previous studies on fine motor skills have largely enrolled treated parkinsonian patients (PP), sometimes taken off

From the Department of Neurology, St. Josef Hospital, Ruhr University Bochum, Gudrunstrasse 56, 44791 Bochum, Germany

Received March 21, 2001. Accepted infinalform September 4, 2001 Reprint requests to: Thomas Müller, Department of Neurology, St. Josef Hospital, Ruhr University Bochum, Gudrunstrasse 56, 44791 Bochum, Germany 
medication for at least 12 hours. ${ }^{15}$ Predominantly, these trials did not consider acute effects of prior application of dopaminergic drugs on their test outcomes. Moreover, no study has compared results of instrumental tasks in previously untreated PP and treated non-fluctuating PP after the standardized intake of an antiparkinsonian compound, since chronic dopaminergic therapy influences task performance. ${ }^{16}$

The objectives of this study were to determine the impact of long-term dopaminergic therapy within a standardized levodopa challenge test design using instrumental tasks.

\section{MATERIAL AND METHODS}

\section{Subjects}

Table 1 shows clinical characteristics of the PP. All were inpatients. They received hospital food without a low protein diet. All fulfilled clinical diagnostic criteria for PD. ${ }^{17}$ Scores of unified Parkinson's disease rating scales (UPDRS) II $(\mathrm{p}=0.03)$ and UPDRS III $(\mathrm{p}=0.04)$ significantly differed between treated and untreated PP, but there was no difference between them in age, Hoehn and Yahr (H\&Y) scale range, UPDRS, and Beck's Depression Inventory (BDI) score. We also performed the tests in 30 age- and sex-matched healthy controls. Participants had no cerebral parenchymal lesion or atrophy nor signs of dementia. They were not exposed to drugs that might potentially influence the dopaminergic system.

\section{Design}

Parkinsonian patients took $250 \mathrm{mg}$ levodopa/benserazide $\left(\right.$ Madopar $\left.^{\circledR}\right)$ within a standardized protocol that minimized factors such as absorption of levodopa, sleep deficits, etc. ${ }^{18,19}$ All were taken off medication for at least twelve hours before test performance. Oral application of the peripherally acting dopamine receptor blocker domperidone (Motilium ${ }^{\circledR}$ ) (40 mg t.i.d.) reduced the intensity and appearance of side effects after levodopa intake. ${ }^{20}$ The last administration of $40 \mathrm{mg}$ domperidone was 30 minutes before levodopa application. We performed testing before (time point: $0=$ baseline), then 30, 60 and 90 minutes after levodopa intake in combination with simultaneous scoring of PP with UPDRS III. ${ }^{21}$ Raters were blinded to the results.

\section{Peg insertion}

We asked subjects to transfer 25 pegs (diameter $2.5 \mathrm{~mm}$, length $5 \mathrm{~cm}$ ) individually from a rack into one of 25 holes (diameter $2.8 \mathrm{~mm}$ ) in a computer-based contact board as quickly as possible. The distance between rack and appropriate holes was $32 \mathrm{~cm}$. The board was positioned in the center and the task was carried out on each side. When transferring each peg from rack to hole, elbows were allowed to be in contact with the table. We measured the time interval between insertion of the first and the last pin, initially with the right- and then the left hand. We assessed the time period for this task to $100 \mathrm{~ms}$ accuracy using a computer. The peg insertion result (Table 2) represented the time of the task performance with the right and left hand in $\mathrm{ms}^{22}$

\section{Tapping}

Individuals tapped as quickly as possible on a contact board $(3 \mathrm{~cm} \times 3 \mathrm{~cm})$ with a contact pencil for a period of 32 seconds
Table 1: Clinical characteristics

\begin{tabular}{lcccc}
\hline & \multicolumn{2}{c}{ untreated PP } & \multicolumn{2}{c}{ treated PP } \\
number & \multicolumn{2}{c}{16} & \multicolumn{2}{c}{14} \\
sex & female: 5 & male: 11 & female: 1 & male: 13 \\
& mean \pm SD & range & mean \pm SD & range \\
age (years) & $54.9 \pm 10.9$ & $29-69$ & $61.1 \pm 7.1$ & $47-72$ \\
H\&YS & $2.3 \pm 0.7$ & I - III & $2.3 \pm 0.7$ & I - III \\
UPDRS I & $0.9 \pm 1.2$ & $0-4$ & $1.5 \pm 1.5$ & $0-5$ \\
UPDRS II & $6.8 \pm 3.5$ & $2-15$ & $10 \pm 4$ & $1-15$ \\
UPDRS III & $25.7 \pm 12.6$ & $11-49$ & $34.6 \pm 12.7$ & $20-64$ \\
BDI & $6.4 \pm 3.9$ & $0-14$ & $7.2 \pm 6.5$ & $0-18$ \\
LD/C or B & & & 3 & \\
LD/C or B + DA & & & 10 & \\
DA & & & 1 & \\
\end{tabular}

Legend: $\mathrm{B}=$ benserazide, $\mathrm{C}=$ carbidopa, $\mathrm{DA}=$ Dopamine agonist; $\mathrm{BDI}$ = Beck's Depression Inventory; H\&YS = Hoehn and Yahr Scale; LD = levodopa, $\mathrm{SD}=$ standard deviation; $\mathrm{PP}=$ parkinsonian patients; UPDRS = Unified Parkinson's Disease Rating Scale; I = mental behaviour; II = activities of daily living; III = motor examination.

after the initial flash of a yellow stimulus light. We did not control for peak height reached by the pencil. The board was positioned in the center and the task was carried out on each side. When performing the task, elbows were allowed to be in contact with the table. We obtained the number of contacts using a computer. We measured the frequency of tapping with the right and then with the left hand. The tapping rate represented the sum of tapping results of both hands (Table 2). ${ }^{22}$

We allowed all participants to get familiar with both tasks for a time interval of 60 seconds to reduce learning or avoid training effects on test performance. ${ }^{23,24}$

\section{Statistics}

Data showed a normal distribution according to the Kolmogorow-Smirnow test. As a result, we only performed parametric tests. We used ANCOVA with repeated measures design including UPDRS I, II, III, BDI-score, sex and age as covariates. Then we performed a post hoc analysis with planned comparisons of data of both instrumental tasks and UPDRS III scores of both arms (selection of items according to Müller et $\mathrm{al}^{25}$ ) at baseline versus measurements after 30,60 and 90 minutes. Comparisons between PP and controls were computed with the t-test for independent samples with an $\alpha$-adjustment to 0.025 in each group. We calculated the mean change of UPDRS III arm score and data of both motoric tasks at the various time points with the formula: $([30 \mathrm{~min}]+[60 \mathrm{~min}]+[90 \mathrm{~min}]) / 3-[0 \mathrm{~min}]$ $=$ mean change. We did not additionally compute results for each side separately in order to reduce the amount of data and calculations. Linear regression was employed for correlation analysis. P-values below 0.05 were significant.

\section{Ethics}

Each subject gave informed consent. The local ethical committee approved this study. 
Table 2: Data at various time points of previously untreated-, treated PP and matched controls

\begin{tabular}{|c|c|c|c|c|c|c|c|c|c|c|c|}
\hline \multirow{2}{*}{\multicolumn{2}{|c|}{ time point }} & \multirow[t]{2}{*}{$\mathrm{CO}$} & \multicolumn{4}{|c|}{ previously untreated PP } & \multirow[t]{2}{*}{$\mathrm{CO}$} & \multicolumn{4}{|c|}{ treated PP } \\
\hline & & & 0 & 30 & 60 & 90 & & 0 & 30 & 60 & 90 \\
\hline \multirow[t]{2}{*}{$\mathrm{T}$} & mean $\pm \mathrm{SD}$ & $370.3 \pm 29.0$ & $320.9 \pm 45.7$ & $306.0 \pm 48.9$ & $305.9 \pm 54.3$ & $306.8 \pm 53.3$ & $359.1 \pm 40.3$ & $302.4 \pm 62.6$ & $296.3 \pm 59.4$ & $298.3 \pm 65.0$ & 305.1 \\
\hline & range & $325-422$ & $242-402$ & $186-385$ & $190-394$ & $213-389$ & $280-414$ & $142-391$ & $144-373$ & $153-390$ & 160 \\
\hline \multirow[t]{3}{*}{ PIS } & mean \pm SD & $808.9 \pm 93.5$ & $1073.1 \pm 233.4$ & $1012.7 \pm 174.8$ & $990.4 \pm 160.3$ & $984.5 \pm 178.7$ & $860 \pm 116$ & $1168 \pm 193.1$ & $1109.3 \pm 205.3$ & $1089.4 \pm 191.8$ & $1070 \pm 199.6$ \\
\hline & range & $645-1072$ & $796-1623$ & $776-1314$ & $741-1227$ & $749-1317$ & $645-1072$ & $863-1551$ & $828-1499$ & $836-1487$ & $812-1531$ \\
\hline & $\mathbf{p}$ & & & 0.013 & 0.001 & 0.0004 & & & 0.09 & 0.02 & 0.006 \\
\hline & range & & $3-27$ & $1-25$ & $2-26$ & $2-22$ & & $11-35$ & $8-33$ & $8-28$ & $9-31$ \\
\hline & $\mathbf{p}$ & & & $6.3 \mathrm{E}-0.7$ & 2.4E-05 & $3.9 \mathrm{E}-0.6$ & & & 0.0003 & $6.6 \mathrm{E}-0.5$ & $2.3 \mathrm{E}-0.5$ \\
\hline
\end{tabular}

$\mathrm{T}=$ Tapping rate; PIS = time interval for peg insertion [ms]; $\mathrm{p}=\mathrm{p}$-values of planned comparisons (post hoc analysis) between baseline data (0) and measurements 30, 60 and 90 minutes after levodopa intake in both groups of parkinsonian subjects (significant p-values are bold); U = UPDRS III arm score; $\mathrm{SD}=$ standard deviation; $\mathrm{PP}=$ parkinsonian patients; $\mathrm{CO}=$ controls, 0 = baseline before levodopa/benserazide intake; $30,60,90$ minutes after levodopa/benserazide intake.

\section{RESUlts}

\section{Comparisons}

There were significant differences of tapping rates (previously untreated PP: $p=0.001$; treated PP: $p=0.009$ ) and peg insertion results (previously untreated PP: $p=0.0002$; treated PP: $\mathrm{p}=2.47 \mathrm{E}-05$ ) of PP in comparison with controls.

Tapping significantly worsened after intake of levodopa in previously untreated $\mathrm{PP}\left(\mathrm{F}_{(\mathrm{dF} 3, \mathrm{dF} 45)}=4.70, \mathrm{p}=0.006\right.$; effect of covariates: $F$ (Wilks' Lambda) $=0.04, p=0.23$ ). Treated PP showed no significant change of tapping after levodopa intake $\left(\mathrm{F}_{(\mathrm{dF} 3, \mathrm{dF} 39)}=0.56, \mathrm{p}=0.64\right.$; effect of covariates: $\mathrm{F}=0.18, \mathrm{p}=$ 0.27 ) (Table 2).

Time intervals for peg insertion significantly shortened after intake of levodopa in previously untreated $\mathrm{PP}\left(\mathrm{F}_{(\mathrm{dF} 3, \mathrm{dF} 45)}=5.94\right.$, $\mathrm{p}=0.0016$; effect of covariates: $\mathrm{F}=0.03, \mathrm{p}=0.14)$ and in treated $\mathrm{PP}\left(\mathrm{F}_{(\mathrm{dF} 3, \mathrm{dF} 39)}=3.19, \mathrm{p}=0.034\right.$; effect of covariates: $\mathrm{F}=0.01$, $\mathrm{p}=0.09$ ) (Table 2).

Scored motor symptoms of both arms significantly improved in de novo $\mathrm{PP}\left(\mathrm{F}_{(\mathrm{dF} 3, \mathrm{dF} 45)}=14.20, \mathrm{p}=1.21 \mathrm{E}-06\right.$; effect of covariates: $\mathrm{F}=0.006, \mathrm{p}=0.006$ [UPDRS III at 0 min: Beta $($ regression coefficient $)=0.57, \mathrm{p}=0.001 ; 30 \mathrm{~min}:$ Beta $=0.55, \mathrm{p}$ $=0.003 ; 60$ min: Beta $=0.48, \mathrm{p}=0.006 ; 90 \mathrm{~min}:$ Beta $=0.42, \mathrm{p}$ $=0.001])$ and treated $\mathrm{PP}\left(\mathrm{F}_{(\mathrm{dF} 3, \mathrm{dF} 39)}=11.39, \mathrm{p}=1.7\right.$; effect of covariates: $\mathrm{F}=0.001, \mathrm{p}=4.3 \mathrm{E}-09$ [UPDRS III at 0 min: Beta $=$ $0.52, \mathrm{p}=9.12 \mathrm{E}-05 ; 30 \mathrm{~min}:$ Beta $=0.61, \mathrm{p}=0.001 ; 60 \mathrm{~min}:$ Beta $=0.39, \mathrm{p}=0.01 ; 90 \mathrm{~min}=$ Beta: $0.44, \mathrm{p}=0.015])($ Table 2$)$.

\section{Correlation analysis}

No significant associations appeared between changes of UPDRS III arm scores and of results of both tests in treated and previously untreated PP. There were no correlations between the changes of tapping and peg insertion in both groups of PP. No significant impact of age, BDI-, UPDRS I-, UPDRS II-, UPDRS III-arm score were found on the results of the tests in both groups with the exception of significant correlations between results of the instrumental tests and UPDRS I (peg insertion: $\mathrm{R}=0.51$; $\mathrm{p}=$
0.04; tapping: $\mathrm{R}=-0.51 ; \mathrm{p}=0.046$ ), UPDRS part II (peg insertion: $\mathrm{R}=0.56 ; \mathrm{p}=0.023$ ) and UPDRS III (arm) score (inserting of pegs: $\mathrm{R}=0.57 ; \mathrm{p}=0.021$ ) in untreated PP. No influence of sex or age on tests appeared in the controls. No serious adverse events occurred in either group. Seven PP (untreated: four; treated: three) complained of fatigue. Yawning did not appear.

\section{Discussion}

Both instrumental tasks differed between PP and controls, but a certain overlap of data occurred with both methods (Table 2). ${ }^{22}$ Both tests only reflect motor impairment of upper limbs with a certain superiority of the pegboard-like task due to the significant correlations between scored motor impairment and test outcomes. ${ }^{10,22}$ They do not represent specific diagnostic markers for PD, because other diseases or fatigue may also influence fine motor skills. ${ }^{26,27}$

UPDRS III arm scores and time periods for peg insertion significantly improved after levodopa application. The delayed response of treated PPin the pegboard-like task may result from delayed gastrointestinal absorption of levodopa, a typical problem of advanced PD. ${ }^{28}$

The main finding of our study is the significant worsening of the tapping rate in previously untreated PP in contrast to treated PPafter levodopa intake. This deterioration of tapping abilities in previously untreated PP could result from an upregulated presynaptic inhibitory feedback regulation, particularly in the dorsal putamen. ${ }^{29-31}$ This feedback mechanism may act to maintain congruity within the dopaminergic system in response to dopaminergic drugs. ${ }^{32,33}$ However, chronic dopaminergic therapy diminishes this autoreceptor function mediated inhibitory feedback regulation and induces some slowly evolving postsynaptic pharmacodynamic changes in the central nervous system. ${ }^{32,34}$ Therefore, treated PPshowed no decrease of tapping rates. Moreover, tapping represents a task with repetitive performance and programming of standardized movements. This 
requires less cognitive effort, since the subject may create a fixed habit tendency with a consistent, attentional saving of cognitive resources. ${ }^{26,35-37}$ In this regard, individuals seem to help themselves during their tapping procedure by learning a standardized performance of a certain sequence of movements based on automatic function of a cognitive set. ${ }^{35,36}$ This more automatic functioning of the attentional control and selective attentional processing is relatively intact in PD. ${ }^{38-40}$ In contrast, performance of inserting of pegs requires more complex sequences of movements. Thus, this task is more dependent on visuospatial cognition, self-elaboration of internal strategies, sorting and planning, all of which are influenced by the modulatory role of the basal ganglia on association areas of the prefrontal cortex..$^{40}$ Therefore, this test is more vulnerable to parkinsonian attention and cognition deficits. ${ }^{35,38,39,41}$ This cognitive deficit results from a dysfunction of dopaminergic pathways of mesial and dorsolateral prefrontal regions due to the dopaminergic deficit in the caudate. ${ }^{37,40,42}$ Peg insertion improved after levodopa intake, since striatal brain dopamine levels modulate movement. ${ }^{37,42,43}$ Moreover, inserting of pegs needs shifting complex information processing requiring different kinds of visual, cognitive and sensory inputs, all of which are altered in PD. ${ }^{38,39,41}$ Additionally, performance of peg insertion repeatedly involves the subject in novel situations and therefore requires greater cognitive efforts. ${ }^{42}$ This test seems to be less sensitive to sedative modes of action of levodopa, since paradigms with a need for greater cognitive efforts are less susceptible to fatigue. ${ }^{35,36,41,44}$ There is growing but controversial evidence for dopamine receptor-mediated sedation, since PP often complain of fatigue following intake of dopaminergic drugs and clinicians have observed yawning as an aura for onset of levodopa-induced "on" phases in PD. ${ }^{45-47}$ Long-term dopaminergic stimulation induces tolerance to nausea and hypotension, but no study has demonstrated tolerance to fatigue. ${ }^{48}$ Our results of reduced tapping abilities in previously untreated PP may support the hypothesis that there is greater sedation from less dopamine tolerance. ${ }^{44}$

A further explaination for the worsening of tapping in de novo PP is that there is overdosing of levodopa. Dopamine overflow reduces cognition processing speed in the prefrontal cortex, disturbs the balance between cholinergic and dopaminergic neurotransmission and causes a reduced cholinergic function in prefrontal areas. ${ }^{49-52}$ Treated PP were not sensitive to dopamine overflow because of their striatal dopaminergic deficit or their previous dopaminergic therapy.

As we did not compare two exactly matched groups of PP, we used age, UPDRS and BDI scores as covariates in the statistical analysis. Varying plasma halflife of levodopa could also influence our results, therefore we repeatedly performed the tests and the rating with UPDRS III arm. ${ }^{21}$ Additionally, we did not place our participants on low protein diets. Thus, we reduced the impact of proteins and large neutral amino acid levels on absorption, metabolism and transport of levodopa across the blood-brain barrier. ${ }^{28,53-55}$ Our study design cannot exclude the impact of learning on results of tests despite only one minute of training. Therefore, our results perhaps should be repeated in a masked fashion, over a longer period, for instance over four hours, to confirm and expand the observations. ${ }^{56}$ Adirect detailed evaluation of "cognition" would also support the value of such a trial.
In conclusion, our study indicates that results of some tests, perhaps with lower cognitive demands, deteriorate after levodopa application in previously untreated PP but not in long-term treated PP, taken off medication for at least 12 hours. Therefore the usefulness of tapping tasks is questionable and reassessments of these types of protocols may be indicated. ${ }^{11,57}$ Since motor impairment and only peg insertion improved in our trial, future studies should consider the impact of previous long-term dopaminergic substitution and cognitive efforts for performance.

\section{ACKNOWLEDGEMENT}

We thank B. Marchewitz and U. Claussnitzer for technical assistance.

\section{REFERENCES}

1. Henderson L, Kennard C, Crawford TJ, et al. Scales for rating motor impairment in Parkinson's disease: studies of reliability and convergent validity. J Neurol Neurosurg Psychiatry 1991; 54:18-24.

2. Gordon AM, Reilmann R. Getting a grasp on research: does treatment taint testing of parkinsonian patients? [letter]. Brain 1999; 122(8): 1597-1598.

3. Geminiani G, Cesana BM, Tamma F, et al. Interobserver reliability between neurologists in training of Parkinson's disease rating scales. A multicenter study. Mov Disord 1991; 6: 330-335.

4. Hely MA, Chey T, Wilson A, et al. Reliability of the Columbia scale for assessing signs of Parkinson's disease. Mov Disord 1993; 8: 466-472.

5. van Hilten JJ, Hoff JI, Middelkoop HA, Roos RA. The clinimetrics of hypokinesia in Parkinson's disease: subjective versus objective assessment. J Neural Transm Park Dis Dement Sect 1994; 8: 117121.

6. Spieker S, Boose A, Breit S, Dichgans J. Long-term measurement of tremor. Mov Disord 1998; 13 (Suppl 3): 81-84.

7. van Hilten JJ, Middelkoop HA, Kuiper SI, Kramer CG, Roos RA. Where to record motor activity: an evaluation of commonly used sites of placement for activity monitors. Electroencephalogr Clin Neurophysiol 1993; 89: 359-362.

8. Buddenberg LA, Davis C. Test-retest reliability of the Purdue Pegboard Test. Am J Occup Ther 2000; 54: 555-558.

9. Fernald LD Jr, Fernald PS, Rines WB. Purdue Pegboard and differential diagnosis. J Consult Psychol 1966; 30: 279.

10. Vingerhoets FJ, Schulzer M, Calne DB, Snow BJ. Which clinical sign of Parkinson's disease best reflects the nigrostriatal lesion? Ann Neurol 1997; 41: 58-64.

11. Contin M, Riva R, Martinelli P, et al. Concentration-effect relationship of levodopa-benserazide dispersible formulation versus standard form in the treatment of complicated motor response fluctuations in Parkinson's disease. Clin Neuropharmacol 1999; 22: 351-355.

12. Montastruc JL, Rascol O, Senard JM, et al. Sublingual apomorphine in Parkinson's disease: a clinical and pharmacokinetic study. Clin Neuropharmacol 1991; 14: 432-437.

13. Nakamura R, Nagasaki H, Narabayashi H. Disturbances of rhythm formation in patients with Parkinson's disease: part I. Characteristics of tapping response to the periodic signals. Percept Mot Skills 1978; 46: 63-75.

14. Shimoyama I, Ninchoji T, Uemura K. The finger-tapping test. A quantitative analysis. Arch Neurol 1990; 47: 681-684.

15. Langston JW, Widner H, Goetz CG, et al. Core assessment program for intracerebral transplantations (CAPIT). Mov Disord 1992; 7: 2-13.

16. Kulisevsky J, Garcia-Sanchez C, Berthier ML, et al. Chronic effects of dopaminergic replacement on cognitive function in Parkinson's disease: a two-year follow-up study of previously untreated patients. Mov Disord 2000; 15: 613-626.

17. Hughes AJ, Daniel SE, Kilford L, Lees AJ. Accuracy of clinical diagnosis of idiopathic Parkinson's disease: a clinicopathological study of 100 cases. J Neurol Neurosurg Psychiatry 1992; 55: 181-184. 
18. Colosimo C, Merello M, Hughes AJ, Sieradzan K, Lees AJ. Motor response to acute dopaminergic challenge with apomorphine and levodopa in Parkinson's disease: implications for the pathogenesis of the on-off phenomenon. J Neurol Neurosurg Psychiatry 1996; 60: 634-637.

19. Hughes AJ, Lees AJ, Stern GM. Challenge tests to predict the dopaminergic response in untreated Parkinson's disease. Neurology 1991; 41: 1723-1725.

20. Parkes JD. Domperidone and Parkinson's disease. Clin Neuropharmacol 1986; 9: 517-532.

21. Muller T, Woitalla D, Schulz D, et al. Tolcapone increases maximum concentration of levodopa. J Neural Transm 2000; 107: 113-119.

22. Muller T, Schafer S, Kuhn W, Przuntek H. Correlation between tapping and inserting of pegs in Parkinson's disease. Can J Neurol Sci 2000; 27: 311-315.

23. Nutt JG, Lea ES, Van Houten L, Schuff RA, Sexton GJ. Determinants of tapping speed in normal control subjects and subjects with Parkinson's disease: differing effects of brief and continued practice. Mov Disord 2000; 15: 843-849.

24. Soliveri P, Brown RG, Jahanshahi M, Marsden CD. Effect of practice on performance of a skilled motor task in patients with Parkinson's disease. J Neurol Neurosurg Psychiatry 1992; 55: 454-460.

25. Muller T, Eising EG, Reiners C, et al. 2-[123I]-iodolisuride SPET visualizes dopaminergic loss in de novo parkinsonian patients: is it a marker of striatal pre-synaptic degeneration? Nucl Med Commun 1997; 18: 1115-1121.

26. Brown RG, Jahanshahi M, Marsden CD. The execution of bimanual movements in patients with Parkinson's, Huntington's and cerebellar disease. J Neurol Neurosurg Psychiatry 1993; 56: 295-297.

27. Ziv I, Avraham M, Michaelov Y, et al. Enhanced fatigue during motor performance in patients with Parkinson's disease. Neurology 1998; 51: 1583-1586.

28. Quigley EM. Gastrointestinal dysfunction in Parkinson's disease. Semin Neurol 1996; 16: 245-250.

29. Ichise M, Kim YJ, Erami SS, et al. Functional morphometry of the striatum in Parkinson's disease on three- dimensional surface display of [123I]- $\beta$-CITSPECT data. J Nucl Med 1999;40:530-538.

30. Marsden CD, Parkes JD. "On-off" effects in patients with Parkinson's disease on chronic levodopa therapy. Lancet 1976; 1: 292-296.

31. Tolosa E, Valldeoriola F. Mid-stage parkinsonism with mild motor fluctuations. Clin Neuropharmacol 1994; 17 Suppl 2: S19-S31.

32. Ekesbo A, Rydin E, Torstenson R, et al. Dopamine autoreceptor function is lost in advanced Parkinson's disease. Neurology 1999; 52: $120-125$.

33. Rioux L, Frohna PA, Joyce JN, Schneider JS. The effects of chronic levodopa treatment on pre- and postsynaptic markers of dopaminergic function in striatum of parkinsonian monkeys. Mov Disord 1997; 12: 148-158.

34. Antonini A, Schwarz J, Oertel WH, Pogarell O, Leenders KL. Longterm changes of striatal dopamine D2 receptors in patients with Parkinson's disease: a study with positron emission tomography and [11C]raclopride. Mov Disord 1997; 12: 33-38.

35. Brown RG, Marsden CD. Internal versus external cues and the control of attention in Parkinson's disease. Brain 1988; 111 ( Pt 2): 323-345.

36. Brown RG, Marsden CD. Cognitive function in Parkinson's disease: from description to theory. Trends Neurosci 1990; 13: 21-29.
37. Lalonde R, Botez-Marquard $\mathrm{T}$. The neurobiological basis of movement initiation. Rev Neurosci 1997; 8: 35-54.

38. Claus JJ, Mohr E. Attentional deficits in Alzheimer's, Parkinson's, and Huntington's diseases. Acta Neurol Scand 1996; 93: 346351.

39. Meco G, Gasparini M, Doricchi F. Attentional functions in multiple system atrophy and Parkinson's disease. J Neurol Neurosurg Psychiatry 1996; 60: 393-398.

40. Dubois B, Pillon B. Cognitive deficits in Parkinson's disease. J Neurol 1997; 244: 2-8.

41. Brown RG, Marsden CD. Dual task performance and processing resources in normal subjects and patients with Parkinson's disease. Brain 1991; 114 ( Pt 1A): 215-231.

42. Dubois B, Pillon B. Do cognitive changes of Parkinson's disease result from dopamine depletion? J Neural Transm Suppl 1995; 45: 27-34.

43. Dunnewold RJ, Jacobi CE, van Hilten JJ. Quantitative assessment of bradykinesia in patients with Parkinson's disease. J Neurosci Methods 1997; 74: 107-112.

44. Andreu N, Chale JJ, Senard JM, et al. L-Dopa-induced sedation: a double-blind crossover controlled study versus triazolam and placebo in healthy volunteers. Clin Neuropharmacol 1999; 22: $15-23$.

45. Olanow CW, Schapira AH, Roth T.Waking up to sleep episodes in Parkinson's disease. Mov Disord 2000; 15: 212-215.

46. Ferreira JJ, Galitzky M, Montastruc JL, Rascol O. Sleep attacks and Parkinson's disease treatment [letter][see comments]. Lancet 2000; 355: 1333-1334.

47. Goren JL, Friedman JH. Yawning as an aura for an L-dopa-induced "on" in Parkinson's disease. Neurology 1998; 50: 823.

48. Montastruc JL, Llau ME, Senard JM, et al. A study of tolerance to apomorphine. Br J Pharmacol 1996; 117: 781-786.

49. Prasher D, Findley L. Dopaminergic induced changes in cognitive and motor processing in Parkinson's disease: an electrophysiological investigation. J Neurol Neurosurg Psychiatry 1991; 54: 603-609.

50. Friedman JI, Temporini H, Davis KL. Pharmacologic strategies for augmenting cognitive performance in schizophrenia. Biol Psychiatry 1999; 45: 1-16.

51. Iversen SD. The pharmacology of memory. C R Acad Sci III 1998; 321: 209-215

52. Yang CR, Mogenson GJ. Dopaminergic modulation of cholinergic responses in rat medial prefrontal cortex: an electrophysiological study. Brain Res 1990; 524: 271-281.

53. Carter JH, Nutt JG, Woodward WR, Hatcher LF, Trotman TL. Amount and distribution of dietary protein affects clinical response to levodopa in Parkinson's disease. Neurology 1989; 39: 552-556.

54. Berry EM, Growdon JH, Wurtman JJ, Caballero B, Wurtman RJ. A balanced carbohydrate: protein diet in the management of Parkinson's disease. Neurology 1991; 41: 1295-1297.

55. Robertson DR, Higginson I, Macklin BS, et al. The influence of protein containing meals on the pharmacokinetics of levodopa in healthy volunteers. Br J Clin Pharmacol 1991; 31: 413-417.

56. Shinotoh H, Vingerhoets FJ, Lee CS, et al. Lamotrigine trial in idiopathic parkinsonism: a double-blind, placebo-controlled, crossover study. Neurology 1997; 48: 1282-1285.

57. Kimber TE, Tsai CS, Semmler J, Brophy BP, Thompson PD. Voluntary movement after pallidotomy in severe Parkinson's disease. Brain 1999; 122(5): 895-906. 